\title{
Pense e ação: quando a representação ilustrativa contribui para a formação/revisão conceitual de elementos da matemática básica
}

Think and action: when the illustrative representation contributes to the conceptual formation / revision of elements of basic mathematics

\author{
Mateus Gianni Fonseca* \\ Juliana Campos Sabino de Souza** \\ Caroline Barbosa Farias Mourão*** \\ Paulo Henrique Sales Wanderley ${ }^{* * *}$
}

\section{Resumo}

Trata-se da apresentação de um dos três jogos criados no ano de 2017 pela equipe organizadora do MatematizAção, evento satélite da Semana Nacional de Ciência e Tecnologia, SNCT 2017 que ocorreu no Instituto Federal de Educação, Ciência e Tecnologia de Brasília - IFB, campus Ceilândia, e fora financiado pelo Fundo de Apoio à Pesquisa do Distrito Federal - FAP/DF. Trata-se do produto intitulado por "Pense e Ação", um jogo coletivo que estimula a interação dos participantes no pensar sobre as diferentes maneiras de representação de conceitos da matemática básica. Esse produto demonstrou grande potencial de envolvimento dos jogadores, bem como uma dinâmica de valia quando se espera estimular os estudantes quanto à motivação/curiosidade de se revisitar conceitos matemáticos outrora estudados. Acredita-se ainda que esse jogo favorece habilidades ligadas à resolução de problemas e criatividade em matemática, na medida em que os jogadores são levados a pensar de diferentes maneiras a fim de conseguir demonstrar cada elemento matemático que deve ser representado ao longo do jogo.

Palavras-chave: Popularização da matemática. Jogo matemático. Pense e Ação.

\footnotetext{
Mestre em Educação - Eixo de interesse Educação Matemática, Avaliação e Criatividade. Docente do Instituto Federal de Educação, Ciência e Tecnologia de Brasília - IFB, mateus.fonseca@ifb.edu.br.

** Mestra em Educação - Eixo de interesse Educação Matemática, Avaliação e Criatividade. Docente do Instituto Federal de Educação, Ciência e Tecnologia de Brasília - IFB, juliana.souza@ifb.edu.br.

Doutora em Biologia Molecular. Docente do Instituto Federal de Educação, Ciência e Tecnologia de Brasília - IFB, caroline.barbosa@ifb.edu.br.

**** Doutor em Engenharia Elétrica. Docente do Instituto Federal de Educação, Ciência e Tecnologia de Brasília - IFB, paulo.wanderley@ifb.edu.br.
} 


\section{Abstract}

This is the presentation of one of the three games created in 2017 by Matematizacion's organizing team, satellite event of the National Science and Technology Week, SNCT 2017, held at the Federal Institute of Education, Science and Technology of Brasília - IFB, Campus Ceilândia. It was funded by the Federal District Research Support Fund - FAP / DF. It is about the product titled "Think and Action", a collective game that stimulates the participants' interaction in thinking about the different ways of representing elements/concepts in basic mathematics. This product has demonstrated great potential for player involvement as well as a dynamic of value when it is expected to stimulate students about the motivation / curiosity to revisit mathematical elements/concepts previously studied. It is also believed that this game favors problem-solving skills and creativity in mathematics as players are led to think in different ways in order to be able to demonstrate each math element that must be represented throughout the game.

Keywords: Popularization of mathematics. Mathematical game. Think and Action.

\section{Introdução}

Uma pesquisa realizada pelo instituto TIM (SALDAÑA, 2015) revela que uma considerável parcela da população não possui domínio de operações de aritmética, tampouco de elementos usuais e rotineiros como porcentagens, frações e outros - o que ratifica a necessidade da adoção de medidas que colaborem para um fortalecimento do ensino de matemática brasileiro, tal como dados de outras pesquisas também sugerem (IPM, 2012; OECD, 2016).

Assim, a partir desses e de outros resultados, é sensato que o Brasil deve impulsionar a qualidade do ensino de matemática caso deseje conceber cidadãos capazes de atuar no mundo globalizado de hoje, o qual exige a constante resolução de problemas que versam sobre as mais diferentes naturezas, conforme P21 (2016) e Unesco (2006) já pontuam acerca das habilidades necessárias para o século XXI. Conceber uma população incapaz de pensar matematicamente pode fragilizar diversos setores da economia e do desenvolvimento tecnológico.

Vale destacar que os indicadores que evidenciam o frágil domínio em matemática no Brasil não excluem o Distrito Federal, afinal, embora esta unidade federativa apresente média 396 no PISA 2015, um dos mais altos em relação aos outros entes federados do país, ainda se encontra abaixo da média internacional, que fora de 490 
pontos (OCDE, 2016) ${ }^{1}$. E isso, contribui para justificar o desenvolvimento de alternativas que contribuam para a motivação da população brasiliense no estudo da matemática - e que justificou inicialmente a criação do jogo Pense e Ação.

É fato que diversos setores ligados à economia e ao desenvolvimento tecnológico de um país demandam uma população capaz de pensar e fazer matemática, o que pode ser uma das justificativas para a necessária mudança no quadro do ensino de matemática brasileiro. No entanto, vale ressaltar, que o letramento em matemática projeta-se para além do mercado de trabalho, chegando a aspectos ligados à cidadania de cada indivíduo, na medida que, a partir dessa área de saber, cada ser humano possa atuar em atividades elementares do dia a dia como conferir um troco na compra do mercado ou ler uma pesquisa eleitoral. No reconhecer disso, o número de pesquisas em educação matemática é crescente na academia, isto é, de fato, muitas instituições, tais como Universidades e Sociedades Civis, têm se debruçado a incrementar o ensino de matemática brasileiro, o que aumenta a motivação para esta área de estudo.

A perspectiva de um jogo que contribua com a divulgação e a popularização da matemática parece deter potencial a convidar os jogadores a serem estimulados sobre a matemática e sobre como fazer matemática a partir de habilidades que envolvam o trabalho colaborativo, a resolução de problemas, a criatividade em matemática, dentre outros, as quais estão intimamente ligadas ao conceito de educação para o século XXI (UNESCO, 2006; P21, 2016; NEWTON, NEWTON, 2014).

Como uma alternativa lúdica, portanto, que tenha como princípio encorajar estudantes, e público em geral, a refletir sobre conceitos básicos da matemática escolar, é que surge o jogo apresentado. Ademais, espera-se que esse jogo também seja elemento motivador para o encorajamento de maiores discussões da essência matemática dos jogos por professores e pesquisadores que advogam à luz de se estruturar atividades inventivas para e na prática escolar. Assim, acredita-se que o produto aqui apresentado possui impactos positivos para a área de educação matemática, no que tange a propiciar o envolvimento dos jogadores em uma atividade de descontração que permita pensar sobre conceitos matemáticos, bem como sobre formas representativas de ilustrá-los, o que pode em muito fortalecer a compreensão dos jogadores sobre cada elemento.

\footnotetext{
O Brasil se encontra em $65^{\text {a }}$ posição em um ranking acerca do ensino de matemática composto por 70 participantes (OCDE, 2016)
} 


\section{Apresentação do produto educacional}

Esse produto fora inspirado em um tradicional jogo de tabuleiro comercializado em lojas infantis e livrarias cujo princípio é a representação de palavras e expressões do dicionário brasileiro com o uso de mímica e/ou desenho. É jogado em equipes, sendo que a cada rodada, cada equipe deve indicar um representante para a realização da ilustração/mímica para sua equipe.

Um jogo que, embora inicialmente não apresente a matemática como fundamento, possui uma condição de trabalho de pensamento matemático considerável, uma vez que a fluência da equipe em gerar múltiplas ideias durante a mímica de seu representante pode aumentar bastante as chances de acerto de cada palavra, o que muito se aproxima de habilidades ligadas à resolução de problemas, de pensamento crítico, de criatividade em matemática, dentre outros tantos elementos defendidos pelos princípio da educação para o século XXI (UNESCO, 2006; P21, 2016; NEWTON, NEWTON, 2014).

Logo, o Pense e Ação possui regramento e estrutura similar a esse jogo já comercializado, contudo, as palavras apresentadas em cada carta do baralho e que devem ser representadas por mímicas e/ou desenhos são elementos ligados ao contexto da matemática escolar. O jogo completo possui um baralho, dois marcadores para quadro-branco, um apagador e um cavalete com quadro branco. Abaixo, uma das cartas do baralho do jogo:
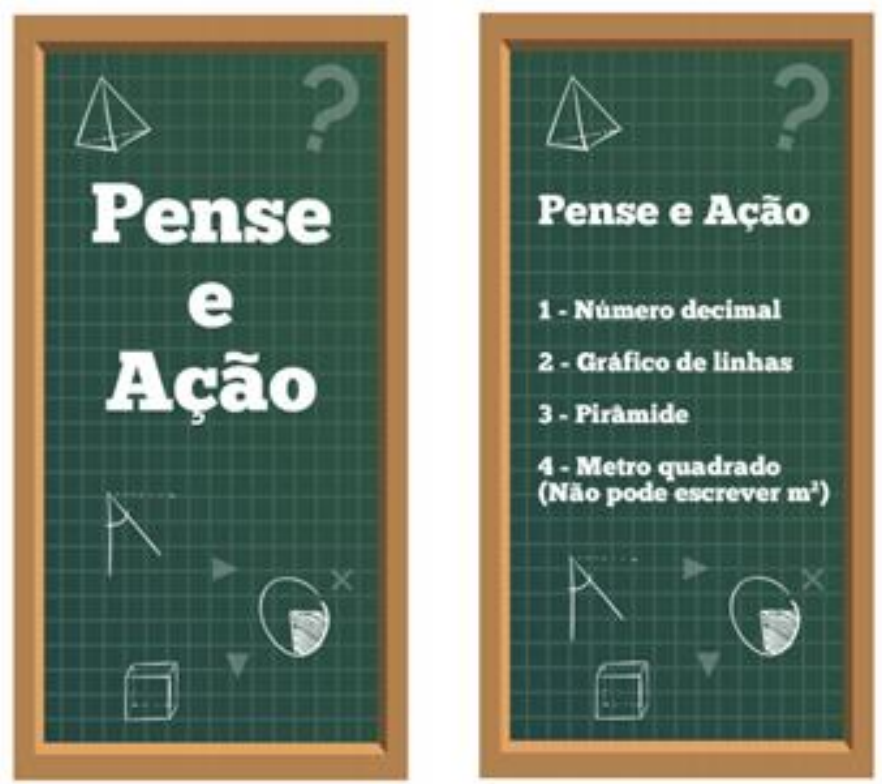

Figura 1 - Modelo de cartas do jogo Pense e Ação. Arquivo da equipe organizadora do Pense e Ação 
Para estimular o envolvimento dos jogadores, as regras são lidas previamente de modo a dirimir as dúvidas e combinar possíveis alterações. Os jogadores são divididos em duas ou três equipes (compostas por no mínimo duas e no máximo quatro pessoas em cada equipe). O jogo é mais rápido e mais emocionante se houver menos equipes e mais jogadores por equipe do que o inverso. Não há problemas caso, havendo um número ímpar de jogadores, uma equipe fique com um jogador a mais que a outra.

As cartas são embaralhadas e colocadas na mesa com a face com os elementos relacionados à matemática para baixo. Cada equipe estabelece, segundo um critério qualquer, a ordem com que os jogadores irão ser os responsáveis por realizar o desenho ou a mímica para o seu grupo acertar, de maneira que há um rodízio nas rodadas seguintes para que todos sejam levados a representar suas equipes como responsáveis pelos desenhos/mímicas.

O representante da equipe que irá fazer a mímica ou o desenho retira uma carta do monte de baralho e tem 20 segundos para examinar a carta. A marcação do tempo inicia e esse jogador começa a desenhar ou fazer mímica para os membros da sua equipe, na tentativa de contribuir para que sua equipe adivinhe o conceito matemático que fora registrado. O representante não pode usar comunicação verbal, por menor que seja. É permitido usar letras, números e símbolos matemáticos desde que não seja escrito a palavra ou parte dela. $O$ representante pode alternar o desenho e a mímica conforme julgar necessário.

Ele continua desenhando ou fazendo mímica e os demais participantes de seu grupo propõem palavras até que alguém diga a palavra certa, ou até que se esgote o tempo. O representante pode desistir de fazer a mímica ou desenho de determinado conceito para prosseguir às outras opções apresentadas na carta e depois retornar ao mesmo dentro do intervalo de noventa segundos. Após transcorrido o tempo da equipe, ou tendo o grupo acertado todas as palavras daquela rodada, a carta que foi usada é colocada com os conceitos para cima em outro monte. Em seguida, outro grupo repete o procedimento até o fim do baralho.

Cada conceito impresso na carta possui um número na frente que representa a pontuação da equipe ao acertar a representação feita pelo colega, sendo assim, após o término da rodada, o representante mostra a carta para os participantes para que, juntos, verifiquem quais conceitos acertaram e, consequentemente, registrem a pontuação obtida. O jogo prossegue desse modo até que o baralho termine. Vale destacar a 
importância que todos os grupos tenham a mesma quantidade de rodadas, então se o baralho estiver acabando e os participantes verificarem que não será possível que todos os grupos realizem uma última rodada, o jogo se encerra sobrando algumas cartas no monte.

Trata-se de um jogo de competição e, portanto, ganha a equipe que tiver a maior pontuação no final do jogo.

\section{Detalhamentos}

Para a confecção do Pense e Ação foram selecionados 108 elementos matemáticos relacionados ao conteúdo do ensino fundamental, o que deu origem a um baralho com 27 cartas, nas quais cada carta possui 4 elementos matemáticos. A esses foram atribuídos 1, 2, 3 e 4 pontos, respectivamente. Dessa maneira, proporcionou-se que todos pudessem jogar, tendo em vista que algum dos elementos sempre eram conhecidos por estudantes a partir do $9^{\circ}$ ano do ensino fundamental (nível escolar utilizado por referência para a elaboração do jogo).

De modo a esclarecer melhor os conceitos apresentados em cada carta, segue 0 detalhamento de uma carta do jogo:

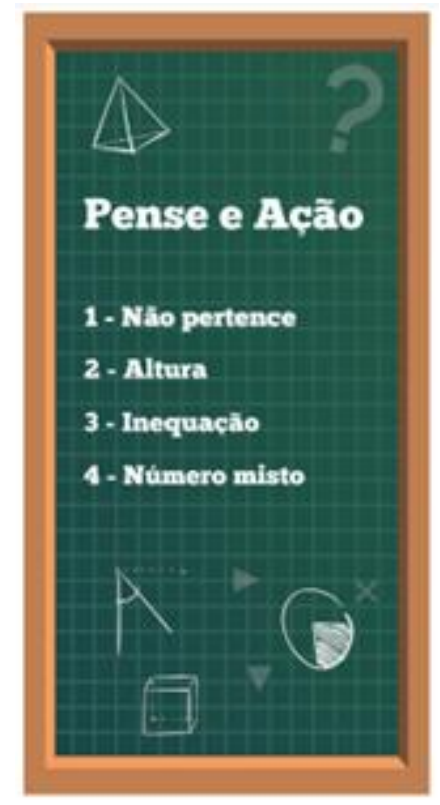

Figura 2 - Carta do pense e ação. Arquivo da equipe organizadora do Pense e Ação 
a) O primeiro elemento é "Não pertence". Classificado como elemento de nível fácil, possui marcação de 1 ponto. A depender da significação que esse elemento matemático possui para o jogador, o mesmo pode simplesmente utilizar do recurso da simbologia, qual seja, $\in$, embora dependa da equipe também recordar do significado desse. Ademais, caso o jogador não se recorde da simbologia, poderá buscar outros recursos como mímica ou até mesmo por situações de conjuntos que levem sua equipe a sugerir este termo, como escrever o número 2 e a nomenclatura $\{1,2,3\}$ e assim por diante;

b) "Altura" é o segundo elemento da carta e, portanto, vale 2 pontos. Aqui espera-se um nível médio de dificuldade. O jogador pode recorrer a vários recursos não necessariamente matemáticos para acertar esse termo, como mímicas indicando sua altura ou coisas do gênero. No entanto, ainda é possível que se desenhe objetos e demarque as medidas de altura para facilitar a resposta que deve ser dada por sua equipe. De fato, em todo o jogo, o representante da equipe deve pensar rápido para não perder o tempo apenas em uma tentativa de representação, isto é, caso uma primeira tentativa de representação do termo 'altura' não tenha tido sucesso, o mesmo pode mudar a estratégia e assim por diante, trabalhando com a flexibilidade de pensamento, enquanto a equipe deve possuir fluidez de ideias, pois às vezes os conceitos representados podem estar bem distantes da melhor representação;

c) Para o nível difícil e sob o valor de 3 pontos, o jogador deve representar à sua equipe o conceito "inequação". Nesse caso, há um detalhe particular: muitos estudantes, em geral, não concebem corretamente as diferenças de uma equação e uma inequação, fato que dificulta o processo de adivinhação do conceito. Novamente, flexibilidade e fluidez devem ser trabalhadas com esse termo, bem como a capacidade de iniciativa de representar algo que, por vezes, o conceito não está bem solidificado junto ao jogador; 
d) Embora número misto seja um elemento trabalhado desde as séries iniciais do ensino fundamental, há de se afirmar que não é algo presente no dia a dia do brasileiro, de maneira que pode ser facilmente esquecido quando não é um elemento utilizado no cotidiano, o que o fez ser caracterizado como 'desafio', no valor de 4 pontos. Caso o representante da equipe não se recorde do conceito formal e/ou de sua representação, deverá recorrer à sua capacidade criativa para representar tal elemento.

Vale destacar aqui que, ao final de cada rodada, os próprios jogadores contribuem com a revisão dos elementos sorteados na medida que ficam curiosos por conhecer aqueles que não conseguiram compreender a representação do jogador da rodada. Logo, ao final de cada rodada, a interação entre os pares faz com que possam relembrar os conceitos e os motivos que levam a determinadas simbologias ou descrições - Eis um momento rico de troca de experiências e que funcionou com muito sucesso ao longo da aplicação do jogo ao longo do evento MatematizAção 2017. Toda a dinâmica presente neste jogo está baseada ainda na ideia de propor pequenos problemas, os quais devem ser resolvidos em tempo curto e cujo recurso principal seja a imaginação e capacidade criativa do jogador.

\section{Relevância do produto educacional}

A ansiedade em matemática, confiança, criatividade, dentre outras, são habilidades e elementos que devem ser considerados quando se objetiva compreender em maior profundidade acerca da relação entre o sujeito e a matemática, conforme pode ser ratificado por Chacón (2003), Onuchic e Allevato (2011) e Polya (1994). Afinal, esses parecem ser elementos atinentes ao aprimoramento do ensino da matemática e que podem ser trabalhados a partir da dinâmica proposta pelo presente jogo.

De fato, não diferente do resto do globo, o país tem investido em estratégias cujo propósito seja de divulgar e popularizar essa área de saber, a matemática, que tanto se demonstra frágil no conhecimento de muitos da sociedade contemporânea. Esse jogo, no entanto, traz como inovação a possibilidade de um material lúdico que permite que a apropriação de conceitos matemáticos seja concebida não apenas com a intervenção do professor, mas com a intervenção dos próprios pares ao final de cada rodada. Crianças, adolescentes e adultos podem jogar com grupos de diferentes faixas etárias, bem como 
de classes escolares - o que ratifica uma estruturação do lúdico a partir da premissa de que são os jogadores os personagens centrais de um processo de leitura e releitura da matemática imersos em um jogo com o propósito de popularização da matemática, estimulando-os a pensar, elaborar estratégias, testar hipóteses e resolver problemas, bem como de nutrir fluência e flexibilidade de pensamento, contribuindo com a criatividade em matemática. Ideais todos defendidos por autores e instituições que defendem a necessidade de um ensino para o século XXI, como Unesco (2006), (P21, 2016) e Newton e Newton (2014).

Um dos resultados esperados na elaboração do presente produto é que os estudantes sejam estimulados a naturalmente proporem conjecturas, analisarem alternativas, realizarem testagens e monitoramentos de resultados - atividades similares a de um matemático profissional, conforme defendido por Nadjafikaha e Yaftiam (2013).

Embora seja um jogo de competição, apresenta-se o presente produto como uma competição saudável que estimula, inclusive, o trabalho colaborativo, na medida em que a equipe se integra a fim de se ajudar mutuamente em prol de acertarem os elementos matemáticos sorteados a cada rodada, bem como as equipes trocam suas percepções de como cada elemento poderia ser melhor representado ao final de cada rodada. No momento em que jogam, os jogadores são tutores deles próprios ao final de cada rodada, o que bem se assemelha com o que Silva (2014, p. 75$)$ relata:

Esse grupo (...) tem como objetivo saber mais e melhor sobre os objetos matemáticos e, nesse sentido, interagem e dialogam a partir situações matemáticas sem que haja predeterminação na direção, no sentido e na forma como circulam os conhecimentos. Assim, ambos podem aprender uns com os outros.

A maneira como cada indivíduo absorve conceitos e cria seu próprio conhecimento é particular a cada um - premissa que pode ser utilizada como base do entendimento de que o jogo que permite a troca de experiência, sobretudo a de troca de experiências pelos pares, pode ser de grande valia, seja para aqueles que ainda não dominam determinado conceito, como para aqueles que se encontram em fase de maturação e ainda para os indivíduos cujo conceito está claro, mas que a partir da troca, podem ainda aprimorá-lo em sua organização/reorganização mental.

Vale destacar que o jogo possui potencial não apenas ao estudante da educação básica, mas também ao professor em formação inicial e/ou continuada. Assim como o estudante, este produto estimula ao jogador refletir sobre elementos/conceitos matemáticos, o que colabora para se 'criar' diferentes formas de representá-los e, 
consequentemente, de compreendê-los. Assim, tanto em situação de formação inicial quanto de formação continuada, o professor poderá alcançar novas ideias para implementar tais elementos/conceitos matemáticos em suas aulas.

\section{Potencial do produto educacional}

O jogo aqui apresentado se configura produto educacional relevante pelos aspectos relatados ao longo deste artigo, bem como, apresenta potencial para se estimular habilidades, sobretudo, ligadas à criatividade em matemática e a agilidade de pensamento. O cenário de um jogo que trata de matemática que contemple diferentes interesses e é capaz de envolver a participação de um grupo de pessoas traz um potencial de ambiente participativo para o desenvolver de outras atividades. Ademais, esse jogo poderia se converter em uma dinâmica de sala de aula na qual que o professor pudesse revisar conceitos e elementos matemáticos dos estudantes, de maneira que ao final de cada rodada pode pudesse propor explicações, pesquisas, entre outros.

É um produto que merece ser observado não apenas como um jogo limitado que somente apenas pode ser replicado a partir da aquisição de material concreto como o baralho, quadro, pincel e apagador, mas como produto educacional que pode ser facilmente adaptado utilizando um papel pardo ou cartolina para os alunos desenharem e um baralho impresso de forma mais simples em uma impressora comum. Ademais, podem os próprios participantes serem convidados a pensarem nos conceitos matemáticos que deverão estar impressos nas cartas, o que potencializa ainda mais as atividades de formação/revisão conceitual dos elementos da matemática.

Vale destacar que o referido jogo também pode ser (re)elaborado para outros níveis da educação, bem como outras áreas do saber, podendo ainda ser oferecido utilizando recursos digitais, como por exemplo por meio de um site ou outro programa computacional que permita a realização de desenhos.

\section{Considerações finais}

Uma primeira concepção do Pense e Ação foi gerada. De acordo com a receptividade do público que conheceu o jogo no evento MatematizAção 2017, espera-se que haja aceitação, popularização e replicação deste tipo de jogo junto a outros públicos e instituições, uma vez que esse demonstra indícios de estímulo a elementos de 
motivação e criatividade de adolescentes e adultos em matemática, seja na forma pura do conceito como na forma representativa que cada sujeito carrega consigo, isto é, a partir da semiótica.

De fato, o envolvimento dos jogadores e, consequente, iniciativa em prol de pensar em meios de representar determinados elementos e conceitos matemáticos vão ao encontro do que muito se tem discutido ao redor do globo no que tange à educação para o século XXI, no que se refere ao trabalho colaborativo, à capacidade comunicativa, ao pensamento crítico e criativo, dentre outras habilidades.

Vale destacar que esse produto foi elaborado utilizando conceitos do nível fundamental, o que não impede que pode ser adaptado para conceitos do ensino médio ou outras componentes curriculares, tal como nada impede de que cartas com diferentes conceitos possam ser estruturadas, inclusive com a participação dos estudantes/jogadores. Afinal, o senso de participação na elaboração do jogo por parte do estudante pode favorecer a maneira pela qual se envolverá no jogo, bem como levará o jogo consigo para a diversão em casa com a família e demais amigos.

Evidentemente, este produto possui limitações. A necessidade de um espaço para se desenhar e para se fazer barulho se faz presente para o desenrolar desse jogo. No entanto, há que se destacar haver muito mais qualidades no jogo que, inclusive, pode ser jogado na sala de aula convencional.

\section{Referências}

CHACÓN, I. M. G. Matemática Emocional: Os Afetos na Aprendizagem Matemática. Porto Alegre: Artmed, 2003.

IPM. Indicador de Alfabetismo Funcional - INAF: Estudo especial sobre alfabetismo e mundo do trabalho. 2016 Disponível em: <https://drive.google.com/file/d/OB5WoZxXFQTCRRWFyakMxOTNyb1k/view>, Acesso em 20 jul. 2017.

NADJAFIKHAHA, Mehdi; YAFTIAN, Narges. The frontage of creativity and Mathematical creativity. Procedia - Social and Behavioral Sciences. Romênia, v. 90, p. 344-350, 2013.

NEWTON, Lynn. D.; NEWTON, Douglas P. Creativity in 21 st century education. Paris, p. 575-589, 2014. 
ONICHIC, Lourdes de la Rosa; ALLEVATO, Norma Suely Gomes. Pesquisa em Resolução de Problemas: caminhos, avanços e novas perspectivas. Bolema, v. 25, n. 41, 2011.

OCDE. Brasil no Pisa 2015: Análises e reflexões sobre o desempenho dos estudantes brasileiros. 2016.

<http://download.inep.gov.br/acoes_internacionais/pisa/resultados/2015/pisa2015_comple to_final_baixa.pdf>, Acesso em 20 jul. 2017.

POLYA, George. A arte de resolver problemas: um novo enfoque do método matemático. Tradução e adaptação: Heitor Lisboa de Araújo. Rio de Janeiro: Interciência, 1994.

P21. Framework for 21st century learning. 2016. Disponível em: <http://www.p21.org/storage/documents/docs/P21_framework_0816.pdf\&gt>, Acesso em 8 mai. 2017.

SALDAÑA, Paulo. Adultos não sabem matemática básica, segundo pesquisa. 2015. Disponível em <http://educacao.estadao.com.br/noticias/geral,adultos-nao-sabemmatematica-basica--segundo-pesquisa,1789357>, Acesso em 17 jul. 2017.

SILVA, E. B. O Diálogo entre diferentes sujeitos que aprendem e ensinam matemática no contexto escolar dos anos finais do ensino fundamental. Tese de Doutorado. Brasília: UnB, 2014.

UNESCO. World conference of arts education: Building creative competences for the 21 st century. 2006. Disponível em: <http://www.artssmarts.ca/media/en/UNESCO_WORLD_CONFERENCE_ON_ARTS_ED UCATION_eng.pdf>, Acesso em 10 jul. 2017. 